\title{
Allelic variation in class I $K$ gene as candidate for a second component of MHC-linked susceptibility to Type 1 diabetes in non-obese diabetic mice
}

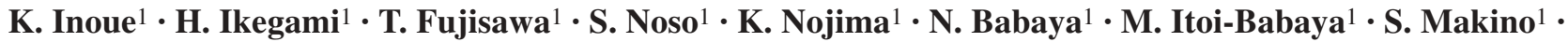 \\ T. Ogihara ${ }^{1}$ \\ ${ }^{1}$ Department of Geriatric Medicine, Osaka University Graduate School of Medicine, Suita, Osaka, Japan
}

\begin{abstract}
Aims/hypothesis. Recent studies have revealed that MHC-linked susceptibility to Type 1 diabetes is determined by multiple components. In the non-obese diabetic (NOD) mouse, a second component (Idd16) has been mapped to a region adjacent to, but distinct from Iddl in the class II region. In this study, we investigated the class I K gene as a candidate gene for Iddl6.

Methods. We determined the genomic sequences of the class $\mathrm{I} K$ gene as well as the reactivity of $\mathrm{K}$ molecules with monoclonal antibodies in the NOD mouse, the Cataract Shionogi (CTS) mouse, and the NOD.CTS- $H-2$ congenic strain, which possesses a resistance allele to Type 1 diabetes at the Idd16 on the NOD genetic background genes.

Results. While the K sequence of the NOD mouse was identical to that of $\mathrm{K}^{\mathrm{d}}$ type, ten nucleotide substitutions were identified in the CTS mouse compared with the NOD mouse. Of these, three were in exon 4, giving
\end{abstract}

two amino acid substitutions, which were identical to those seen in $\mathrm{K}^{\mathrm{K}}$ type. These characteristics were retained in the NOD.CTS- $H-2$ congenic strain, which had a lower incidence and delayed onset of Type 1 diabetes owing to a resistance allele at Idd16. Lymphocytes from NOD.CTS-H2 congenic mice reacted with anti- $\mathrm{K}^{\mathrm{d}}$ and anti- $\mathrm{K}^{\mathrm{k}}$ monoclonal antibodies, reflecting the unique sequence of the $\mathrm{K}$ gene. The nucleotide sequence of the $\mathrm{K}$ gene in the non-obese non-diabetic (NON) mouse was also unique, consisting of a combination of $\mathrm{K}^{\mathrm{k}}$ - and $\mathrm{K}^{\mathrm{b}}$-like sequences.

Conclusions/interpretation. These data suggest that $\mathrm{H} 2-\mathrm{K}$ is unique in CTS and NON mice, and that allelic variation of the class I $\mathrm{K}$ gene may be responsible for Idd16.

Keywords Congenic mouse - CTS mouse - Gene . $\mathrm{H} 2-\mathrm{K} \cdot \mathrm{Idd} 16 \cdot$ Major histocompatibility complex • Monoclonal antibody $\cdot$ Non-obese diabetic mouse . Sequence - Type 1 diabetes
Received: 10 November 2003 / Accepted: 26 January 2004

Published online: 1 April 2004

(C) Springer-Verlag 2004

H. Ikegami (

Department of Geriatric Medicine,

Osaka University Graduate School of Medicine,

2-2 Yamadaoka, Suita, Osaka 565-0871, Japan

E-mail: ikegami@geriat.med.osaka-u.ac.jp

Tel.: +81-6-68793852, Fax: +81-6-68793857

Abbreviations: CTS, Cataract Shionogi .

FACS, fluorescence-activated cell sorter - FITC, fluorescein isothiocyanate $\cdot \mathrm{NOD}$, non-obese diabetic $\cdot \mathrm{NON}$, non-obese non-diabetic $\cdot$ SNP, single nucleotide polymorphism

\section{Introduction}

Type 1 diabetes, which is caused by autoimmune destruction of insulin-producing beta cells of the pancreas, is a polygenic disorder involving multiple-susceptibility genes $[1,2,3]$. Of these, MHC-linked susceptibility has been shown to be the strongest component. In humans, class II HLA genes, and in particular $D R$ and $D Q$ genes, have been shown to confer strong susceptibility. Several recent studies, however, indicated that HLA-linked susceptibility cannot be explained merely by class II $D R$ and $D Q$ genes, and that a gene or genes adjacent to, but distinct from $D R$ and $D Q$ genes, such as genes in the class I region, are also involved in susceptibility to the disease $[4,5,6,7,8,9$, 
10, 11, 12]. However, the strong linkage disequilibrium across the HLA region makes it difficult to dissect MHC-linked susceptibility to Type 1 diabetes into each component.

The non-obese diabetic (NOD) mouse spontaneously develops autoimmune Type 1 diabetes with marked similarities to human Type 1 diabetes. As in the case of human Type 1 diabetes, inheritance of diabetes in the NOD mouse is polygenic and the strongest susceptibility has been mapped to the MHC region on chromosome 17 [13, 14, 15]. A series of studies using NOD strains congenic for the MHC have shown that the class II MHC contributes to susceptibility to Type 1 diabetes. Both NOD mice congenic for the MHC derived from control strains such as C57BL/10 [16], and NOD-related strains such as nonobese non-diabetic (NON) mice [17] were reported to be completely resistant to Type 1 diabetes, indicating that the NOD MHC is necessary for susceptibility to Type 1 diabetes. In contrast, NOD mice congenic for the MHC from the NOD-related Cataract Shionogi (CTS) strain, which possesses the same class II MHC as the NOD mouse, developed Type 1 diabetes [18, 19], indicating that the CTS MHC confers susceptibility to Type 1 diabetes and that the class II MHC is responsible for MHC-linked susceptibility.

While the class II MHC of the NOD mouse is involved in susceptibility, the class II MHC is not sufficient for full expression of the Type 1 diabetes phenotype in the NOD mouse, because NOD mice congenic for the CTS MHC had a markedly lower incidence and delayed onset of Type 1 diabetes, despite having the same class II MHC as the NOD mouse [18, 19]. These data indicate that the strong susceptibility linked to the MHC is due to the combined effect of Iddl in the class II region and another gene or genes outside the class II region. The second component of MHC-linked susceptibility, designated Idd16, was mapped to the $<10.5 \mathrm{cM}$ region adjacent to, but distinct from the class II MHC region containing class I genes [20].

The class I K gene, located centromeric to the class II region, is syntenic to HLA class I genes A, B and C in humans. MHC class I molecules are important for presenting antigens in target cells to cytotoxic $\mathrm{T}$ cells responsible for immune attack, leading to destruction of target cells. In humans and animals MHC class I molecules are divergent among individuals, and this variation, determined by genetic polymorphism, is involved in the divergent immune responses against foreign and self antigens in each animal. In a previous study with serological typing of class I K molecules with monoclonal antibodies, we found that the NOD mouse showed the same reactivity as $\mathrm{K}^{\mathrm{d}}$, whereas the CTS mouse showed a unique reactivity (which was different from any previously known $\mathrm{K}$ molecules), reacting not only with anti- $\mathrm{K}^{\mathrm{d}}$, but also with some anti-K $\mathrm{K}^{\mathrm{k}}$ monoclonal antibodies [21]. Given the role of class I molecules in antigen presentation in the autoimmune process, the class I K gene is a strong functional and positional candidate gene for Idd16. In fact, recent studies using a recombinant $\mathrm{MHC}$ between NOD and a wild-derived strain with high recombination frequency within the MHC mapped a second component of MHC-linked susceptibility to the $1.1 \mathrm{cM}$ region that is proximal to class II and contains the class I K gene [22, 23].

To clarify the genetic basis of the unique reactivity of class I K molecules in NOD-related strains and the possible contribution of allelic variation in the class I $\mathrm{K}$ gene to MHC-linked susceptibility to Type 1 diabetes, we determined the genomic sequences of all exons, exon-intron junctions and the promoter region of the class I $\mathrm{K}$ gene in NOD mice and their sister strains, CTS and NON, as well as in NOD.CTS-H2 congenic mice, which were used for mapping of Idd16.

\section{Materials and methods}

Animals. We used NOD/Shi, NON/Shi and CTS/Shi mice, which were maintained in the colony of Shionogi Aburahi Laboratories (Shiga, Japan). This is the colony from which NOD and CTS mice for congenic mapping [19] and MHC typing $[18,21]$ were derived.

DNA. Genomic DNA was extracted from liver tissue of NOD, NON, CTS and NOD.CTS-H2 congenic mice by a standard method. A total of 13 pairs of primers were designed using Primer3 Input (http://www.genome.wi.mit.edu/cgi-bin/primer/ primer3.cgi), so that the promoter region (approximately $700 \mathrm{bp}$ upstream from transcription initiation site), the 8 exons, and the $3^{\prime}$-UTR of the class I K gene were covered by $13 \mathrm{seg}-$ ments (primer sequences available upon request). Genomic DNA was amplified by PCR with these primers. The PCR products were refined using a Qia quick gel extraction kit (Qiagen, Tokyo, Japan) and subjected to direct sequencing, utilising dye termination chemistry with an ABI Prism 3100 Genetic Analyzer (Applied Biosystems, Tokyo, Japan). To minimise the sequencing artifact, we did direct sequencing of the PCR products with both strands sequenced at least twice in each strain. The sequences were compared with the published sequences of class I K ${ }^{\mathrm{b}}$ (Accession no. M11847) [24, 25], $\mathrm{K}^{\mathrm{d}}$ (Accession no. X01815, U47329) [26], and $\mathrm{K}^{\mathrm{k}}$ (Accession no. X01652) [27], as well as $\mathrm{K}$ from NOD/Lt (Accession no. L36065) [28]. To search for transcription binding sites in the promoter region, we used TFSEARCH (http://www.cbrc.jp/ research/db/TFSEARCHJ.html).

Reactivity of MHC molecules. The reactivity of MHC molecules with monoclonal antibodies was studied by fluores-

Fig. 1. Comparison of nucleotide sequences of promoter regions of $\mathrm{K}^{\mathrm{d}}, \mathrm{K}^{\mathrm{k}}$, NOD and CTS mice. The nucleotide differences between NOD (non-obese diabetic) and CTS (Cataract Shionogi) mice are shown by bold characters at positions: $-217(\mathrm{G} \rightarrow \mathrm{C}),-201(\mathrm{~A} \rightarrow \mathrm{G}),-137(\mathrm{~A} \rightarrow \mathrm{T}),-101(\mathrm{~T} \rightarrow \mathrm{A})$ and $-92(\mathrm{~T} \rightarrow \mathrm{A})$. The TATA box and CAAT box are underlined. Details on sequences and numbering, see Methods section (references [28] and [29]) 

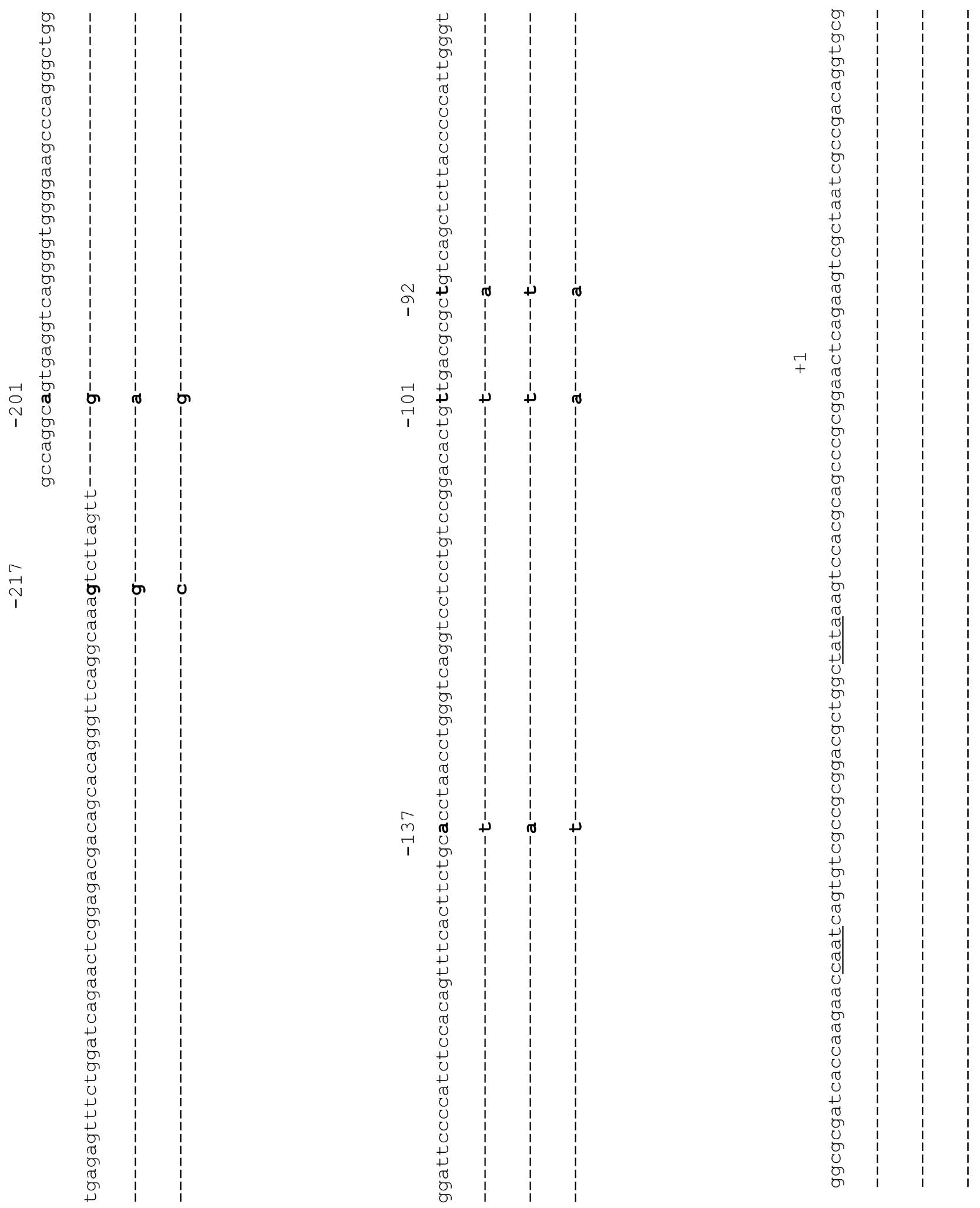

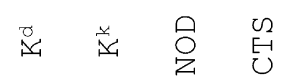

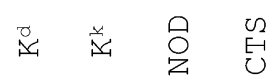

承 
cence-activated cell sorter (FACS) using lymphocytes from NOD/Shi, C3H/He and NOD.CTS-H2 congenic mice. The following monoclonal antibodies were used: 16-1-11N (anti-K $\mathrm{K}^{\mathrm{k}}$, SF1-1.1 (anti-K ${ }^{\mathrm{d}}$ ) and RPC.5.4 (negative control). Fluorescein isothiocyanate (FITC) goat anti-mouse IgG was used as a second antibody. These antibodies were provided by M. Hattori (Joslin Diabetes Center, Boston, Mass., USA). Approximately $10^{6}$ lymphocytes suspended in buffer (RPMI-1640 with 5\% FCS) were incubated for $30 \mathrm{~min}$ at $4{ }^{\circ} \mathrm{C}$ with monoclonal antibodies. The lymphocytes were then washed and incubated for 30 min at $4{ }^{\circ} \mathrm{C}$ with FITC-goat anti-mouse IgG. The counts of positive cells were determined by FACS scan (Becton Dickinson, San Jose, Calif., USA).

\section{Results}

The nucleotide sequences in the NOD/Shi mouse (Accession no. AB114273-114280) were identical to those reported for the promoter and all exons in $\mathrm{BALB} / \mathrm{c}\left(\mathrm{K}^{\mathrm{d}}\right.$ type) [26] and to the cDNA sequences in the NOD/Lt mouse [28]. We found ten single nucleotide polymorphisms (SNPs) between NOD and CTS (Accession no. AB114281-114288) (Fig. 1, Fig. 2). Of these SNPs, five were in the promoter region at position $-217(\mathrm{G} \rightarrow \mathrm{C}),-201 \quad(\mathrm{~A} \rightarrow \mathrm{G}),-137 \quad(\mathrm{~A} \rightarrow \mathrm{T})$, $-101(\mathrm{~T} \rightarrow \mathrm{A})$, and $-92(\mathrm{~T} \rightarrow \mathrm{A})$ (Fig. 1); one was in exon 2 at position $+533(\mathrm{~A} \rightarrow \mathrm{G})$; and the other four were in exon 4 at position $+2767(\mathrm{~T} \rightarrow \mathrm{C}),+2788$ $(\mathrm{G} \rightarrow \mathrm{A}),+2800(\mathrm{~T} \rightarrow \mathrm{A})$, and $+2842(\mathrm{~T} \rightarrow \mathrm{C})$. According to TFSEARCH, the SNPs in the promoter region did not correspond with the binding sites of known transcription factors.

While the SNP in exon 2 (A533G) and one SNP $(\mathrm{T} \rightarrow \mathrm{C}$ at position +2842$)$ in exon 4 were silent polymorphisms, the other three SNPs in exon $4(\mathrm{~T} \rightarrow \mathrm{C}$ at position +2767 , GAT $\rightarrow$ AAA at position +2788 and +2800) were expected to cause two amino acid substitutions, Tyr ${ }^{191}$ (NOD) $\rightarrow$ His $^{191}$ (CTS) and Asp ${ }^{198}$ (NOD) $\rightarrow$ Lys $^{198}$ (CTS) in the $\alpha 3$ domain. These two amino acids, histidine at position 191 and lysine at position 198 , are seen in $\mathrm{K}^{\mathrm{K}}\left(\mathrm{C} 3 \mathrm{H}\right.$ mice), but not $\mathrm{K}^{\mathrm{d}}$ (Fig. 2). Except for these 2 amino acids, the other amino acids were identical to those in $\mathrm{K}^{\mathrm{d}}$ and the NOD mouse.

To confirm that NOD.CTS-H2 congenic mice, which showed a lower incidence and delayed onset of Type 1 diabetes, retain this unique $\mathrm{K}$ molecule, we determined the $\mathrm{K}$ sequence in this strain, finding that the $\mathrm{K}$ sequence of the congenic mouse (Accession no. AB121050) is identical to that in the CTS mouse and different from that in the NOD mouse.

In our previous study, the $\mathrm{K}$ molecule of the NON mouse also showed unique reactivity to anti-K monoclonal antibodies, reacting with both anti- $\mathrm{K}^{\mathrm{b}}$ and anti- $\mathrm{K}^{\mathrm{k}}$ antibodies [21]. We therefore determined the $\mathrm{K}$ sequence of the NON mouse (Accession no. AB114279-114296) which was partially identical to $\mathrm{K}^{\mathrm{b}}$ and partially identical to $\mathrm{K}^{\mathrm{k}}$.
To confirm that the unique sequences of the CTS mouse are reflected in the corresponding molecules, we studied the reactivity of splenocytes with monoclonal antibodies to class I molecules in NOD and CTS mice. The reactivity of $\mathrm{K}$ molecules with monoclonal antibodies correlated with the predicted amino acid sequences of $\mathrm{K}$, in that splenocytes of CTS mice

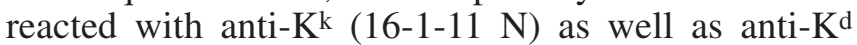
(SF1-1.1).

To confirm that the unique reactivity with anti-K monoclonal antibodies is retained in NOD.CTS-H2 congenic mice whose genome is identical to the NOD mouse except for the Idd16 region, lymphocytes from NOD.CTS-H2 congenic mice were stained with anti-K monoclonal antibodies (Fig. 3). Lymphocytes from NOD.CTS-H2 congenic mice reacted with anti-K $\mathrm{K}^{\mathrm{d}}$ and anti- $\mathrm{K}^{\mathrm{k}}$ monoclonal antibodies, indicating that the unique characteristics of the $\mathrm{K}$ molecule of the CTS mouse are retained in NOD.CTS- $H 2$ congenic mice and reflecting the unique sequence of the $\mathrm{K}$ gene. The fluorescence intensity of lymphocytes stained with anti- $\mathrm{K}^{\mathrm{d}}$ monoclonal antibody in NOD.CTS-H2 congenic mice was similar to that in NOD mice. This suggests that expression of $\mathrm{K}$ molecules is similar between the two strains and that nucleotide substitutions in the promoter region of the CTS allele may not have affected expression of $\mathrm{K}$ molecules.

\section{Discussion}

In this study, we determined the genomic sequences of all eight exons, exon-intron junctions and the promoter region of the $\mathrm{MHC}$ class I $\mathrm{K}$ gene as a candidate gene for Idd16. This was done in the NOD mouse and the CTS mouse, which have susceptible and resistant alleles respectively at Idd16. The nucleotide sequence in the NOD mouse was identical to that reported in $\mathrm{BALB} / \mathrm{c}\left(\mathrm{K}^{\mathrm{d}}\right)$, whereas that in the CTS mouse was different at ten positions from that in the NOD mouse. In particular, three nucleotide substitutions in exon 4 were predicted to cause two amino acid substitutions in the $\alpha 3$ domain. These two amino acids were identical to those found in $\mathrm{K}^{\mathrm{k}}$, while the rest of the molecule was completely identical to $\mathrm{K}^{\mathrm{d}}$. These characteristics of nucleotide sequences were comparable to the char-

Fig. 2. Comparison of nucleotide and predicted amino acid sequences of $\mathrm{H} 2-\mathrm{K}$ gene in exon 4 of $\mathrm{K}^{\mathrm{d}}, \mathrm{K}^{\mathrm{k}}$, NOD and CTS mice. The amino acid sequence is below the nucleotide sequence. Differences in nucleotides and amino acids between NOD (non-obese diabetic) and CTS (Cataract Shionogi) mice are shown by bold characters at positions: $+2767(\mathrm{~T} \rightarrow \mathrm{C})$, $+2788(\mathrm{G} \rightarrow \mathrm{A}),+2800(\mathrm{~T} \rightarrow \mathrm{A})$ and $+2842(\mathrm{~T} \rightarrow \mathrm{C})$. Nucleotide substitutions at $+2767,+2788$ and +2800 are predicted to cause two amino acid substitutions, Tyr (T) (NOD) $\rightarrow$ His (H) (CTS) at residue 191, and Asp (D) (NOD) $\rightarrow$ Lys (K) (CTS) at residue 198. Details on sequences and numbering, see Methods section (references [28] and [29]) 

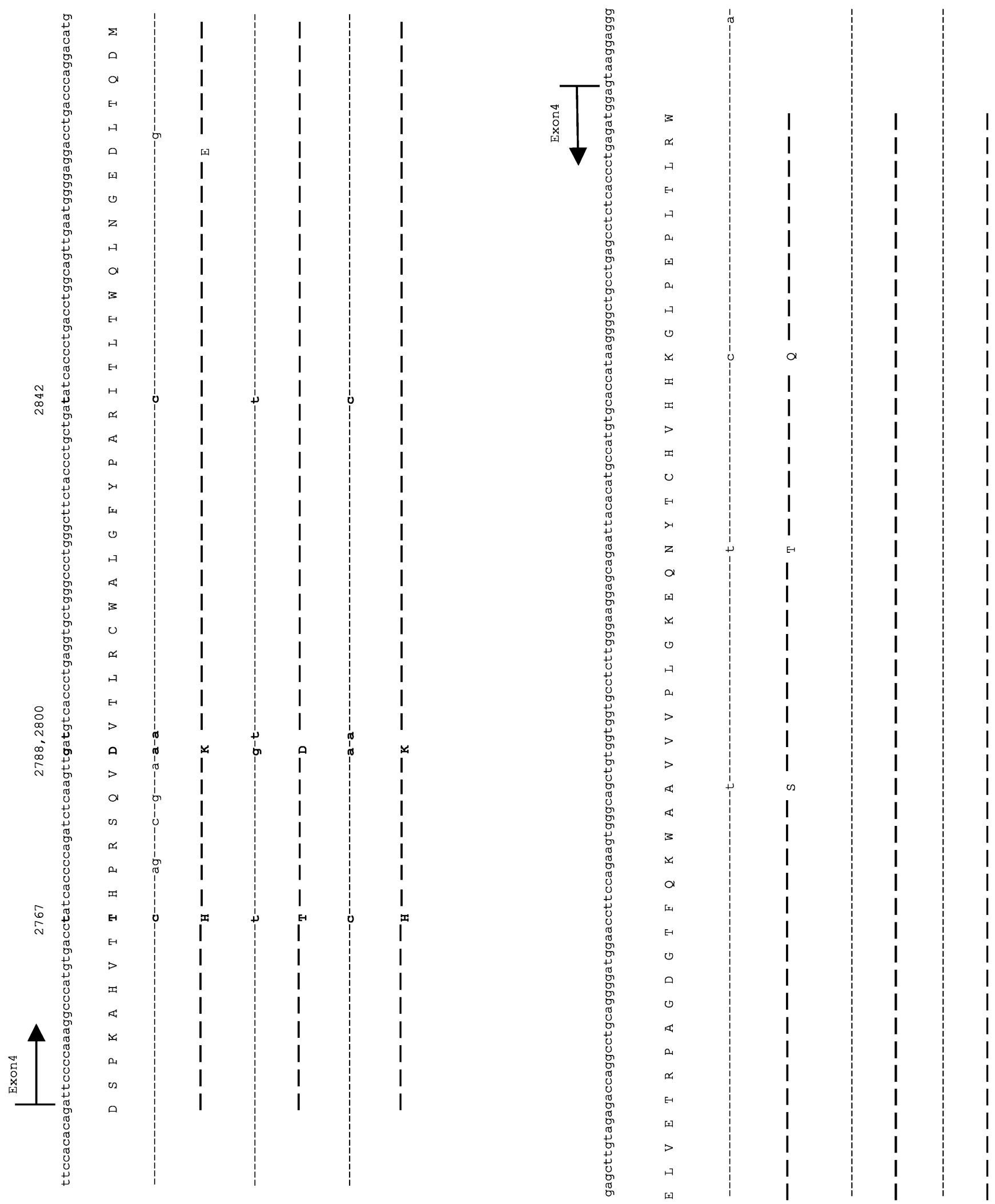

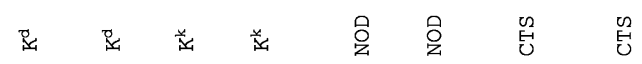

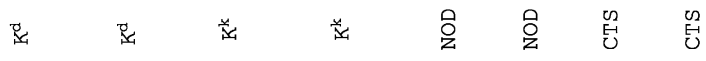



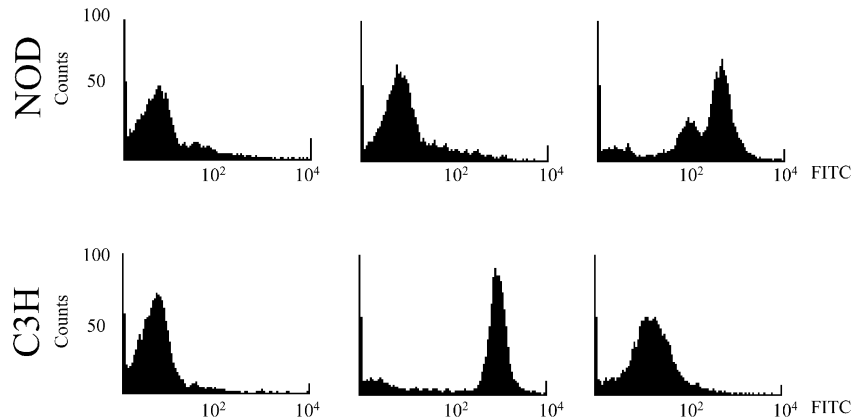

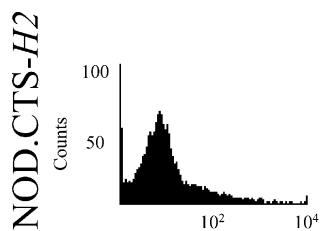

RPC5.4

(Control)

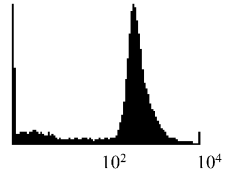

$16-1-11 \mathrm{~N}$

$\left(\right.$ Anti-K $\left.{ }^{k}\right)$

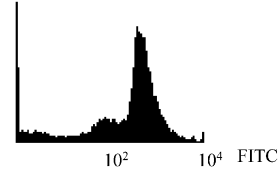

SF1-1.1

$\left(\right.$ Anti-K $\left.{ }^{\mathrm{d}}\right)$
Fig. 3. Comparison of the reactivity of lymphocytes with anti$\mathrm{K}$ monoclonal antibodies in NOD.CTS-H2 congenic and nonobese diabetic (NOD) and $\mathrm{C} 3 \mathrm{H}$ mice. Lymphocytes from NOD.CTS-H2 congenic mice reacted with anti- $\mathrm{K}^{\mathrm{d}}$ and anti- $\mathrm{K}^{\mathrm{k}}$ monoclonal antibodies, while those from NOD mice reacted with anti- $\mathrm{K}^{\mathrm{d}}$ and those from $\mathrm{C} 3 \mathrm{H}$ mice with anti- $\mathrm{K}^{\mathrm{k}}$. The fluorescence intensity of lymphocytes stained with anti- $\mathrm{K}^{\mathrm{d}}$ monoclonal antibodies in NOD.CTS-H2 congenic mice was similar to that in NOD mice. FITC, fluorescein isothiocyanate goat anti-mouse IgG

acteristics of $\mathrm{K}$ molecules of the CTS mouse in their reactivity with monoclonal antibodies in this, as well as previous studies in our [21] and other laboratories [29]. The same unique sequence was also retained in NOD.CTS-H2 congenic mice, which had a lower incidence and delayed onset of Type 1 diabetes. The unique reactivity to anti- $\mathrm{K}$ monoclonal antibodies correlated with the unique sequence of the $\mathrm{K}$ gene in NOD.CTS-H2 congenic mice, as well.

Recently, another congenic strain was used for genetic dissection of MHC-linked susceptibility to Type 1 diabetes. In this strain a recombinational hotspot from the B10.A (R209) mouse was introduced to the region between class I $\mathrm{K}$ and class II A genes of the NOD mouse [22]. The recombination between class I $\mathrm{K}$ and class II A genes created a recombinant MHC with a NOD-derived distal region containing class II A and E genes, and an R209-derived proximal region containing the class I K gene. The frequency of Type 1 diabetes in NOD mice congenic for this recombinant MHC was markedly reduced, despite the presence of the NODderived MHC at IddII (class II A and E genes) [22], indicating that the proximal MHC, containing the class I $\mathrm{K}$ gene, contributes to susceptibility to Type 1 diabetes. In a study using subcongenic strains, this region was recently narrowed down to the $1.1 \mathrm{cM}$ region containing the $\mathrm{K}$ gene [23]. Together, these data suggest that the class $\mathrm{I} \mathrm{K}$ gene is a strong positional candidate for Idd16.
The functional contribution of the class I MHC to the development of Type 1 diabetes was clearly demonstrated by the fact that the NOD mouse lacking class I molecules is completely protected from insulitis and diabetes due to targeted disruption of the $\beta 2$ microglobulin gene $[30,31,32,33]$. Among class I molecules expressed in the NOD mouse, class I $\mathrm{K}^{\mathrm{d}}$ (but not $\mathrm{D}^{\mathrm{b}}$ ) appears to be important because almost all the $\mathrm{CD}^{+} \mathrm{T}$ cells isolated from NOD islets recognise islet antigens in the context of $\mathrm{K}^{\mathrm{d}}$ molecules [34, $35,36,37,38]$. In addition, Type 1 diabetes of the NOD mouse was reported to be prevented by anti-K $\mathrm{K}^{\mathrm{d}}$ monoclonal antibody, but not by anti- $\mathrm{D}^{\mathrm{b}}$ monoclonal antibody [39]. Recently, transgenic expression in NOD mice of $K^{\mathrm{R} 209}$, the $\mathrm{K}$ gene from the B10.A (R209) strain, was also shown to reduce the incidence and delay the onset of Type 1 diabetes [23]. This was shown in the case of NOD.CTS-H2 congenic mice [19] and intra-MHC recombinant NOD mice, which possess the class I K region from R209 [22, 23]. These data, together with the substitutions of $\mathrm{K}^{\mathrm{d}} \mathrm{ob}-$ served here in the NOD mouse, with $\mathrm{K}^{\mathrm{k}}$-like residues in NOD.CTS-H2 congenic mice, suggest that class I $\mathrm{K}^{\mathrm{d}}$ is both a functional and a positional candidate for Idd16.

Although class I $\mathrm{K}$ gene is a strong candidate for Idd16, other genes in the MHC could be responsible for Idd16 effect. A recent study, for example, reported that NOD mice congenic for a 6-cM interval proximal to $\mathrm{H} 2-\mathrm{K}$ from $\mathrm{C} 57 \mathrm{BL} / 6$ strain had a markedly reduced incidence and delayed onset of Type 1 diabetes [40]. Another study reported that at least two, and probably more, distinct genes centromeric to class II genes contribute to diabetes-resistance in NOD mice congenic for the MHC proximal to class II genes from the B10.A (R209) strain [23]. In addition to genes in proximal MHC, genes in distal MHC such as Tnf [41] and class I $D$ [29] have also been suggested as candidates for Idd16. It is possible, therefore, that Idd16 consists of multiple components and that class I K gene is a candidate for one component.

In human Type 1 diabetes mellitus, we previously reported that the HLA class II region is strongly associated with disease susceptibility, whereas age at disease onset is linked to the class I region [5]. Subsequent studies in several ethnic groups also suggested that a gene or genes in the class I region confer or modify susceptibility to Type 1 diabetes [42, 43, 44]. Given the strong effect of HLA gene polymorphisms per se on immune responses, it is possible that HLA class I gene polymorphism modifies autoimmunity through its effect on autoantigen presentation to effector T cells. However, identification of a susceptibility gene outside the class II region in humans is difficult owing to the strong linkage disequilibrium across the HLA region. As a second component of the MHClinked gene has been mapped to the class I region in the NOD mouse, as in humans, the identification of 
non-class II susceptibility genes in the NOD mouse will contribute to a better understanding of the causes of human Type 1 diabetes.

Class I MHC molecules, which consist of a heavy chain ( $\alpha 1, \alpha 2$ and $\alpha 3$ domains) and a light chain ( $\beta 2$ microglobulin), bind short peptide fragments and present them as target antigens to cytotoxic $\mathrm{T}$ cells. The two amino acid substitutions found by comparing the sequences of the class I K gene in NOD and CTS mice, Tyr ${ }^{191}$ (NOD) $\rightarrow$ His $^{191}$ (CTS) and Asp ${ }^{198}$ (NOD) $\rightarrow$ Lys $^{198}$ (CTS), are located in the $\alpha 3$ domain. Substitutions of positively charged aspartate with negatively charged lysine and the aromatic amino acid tyrosine with the basic amino acid histidine may affect the interaction of the $\alpha 3$ domain with $\beta 2$ microglobulin, leading to changes in the three-dimensional structure of the overall molecule. Provided that one amino acid substitution in MHC molecules affects immune responses [45, 46, 47], it is possible that these amino acid substitutions affect the autoimmune response to pancreatic beta cells, leading to a lower incidence and delayed onset of Type 1 diabetes in NOD.CTS-H2 congenic mice.

In addition to amino acid substitutions in exon 4, nucleotide substitutions were found in the promoter region. These may also affect expression of $\mathrm{K}$ molecules. None of the substitutions, however, corresponded to the binding site of known transcription factors. In addition, the similar fluorescence intensity in NOD and NOD.CTS-H2 lymphocytes stained with anti- $\mathrm{K}^{\mathrm{d}}$ monoclonal antibody suggests that nucleotide substitutions in the promoter have little, if any, effect on expression of $\mathrm{K}$ molecules.

The CTS mouse was previously reported to have the same cDNA sequences of the $\mathrm{K}$ gene as the NOD mouse, which has $\mathrm{K}^{\mathrm{d}}$ type [29]. In our study, the CTS/Shi mouse from the original colony turned out to have a unique nucleotide sequence that is different from the NOD sequence, leading to two amino acid substitutions. These substituted amino acids are identical to those found in the $\mathrm{K}^{\mathrm{k}}$ molecule. This result is compatible with the reactivity of $\mathrm{H}-2 \mathrm{~K}$ molecules with monoclonal antibodies in the present study as well as in previous studies from our [21] and other laboratories [29], in that splenocytes from CTS mice reacted with an anti- $\mathrm{K}^{\mathrm{k}}$ monoclonal antibody in addition to an anti- $\mathrm{K}^{\mathrm{d}}$ monoclonal antibody.

The reason for the discrepancies between the sequence in the present study and those reported by Mathews et al. is unknown. One possibility is difference in strains. In the present study, sequences were determined in the CTS/Shi mouse obtained from the original colony at Shionogi Aburahi laboratories, which is the colony from which the CTS mice for original studies on monoclonal antibody reactivity and also for congenic mapping of Idd16 were derived. Another possibility is the difference in the template used for sequence analysis. Genomic DNA was used in the present study, whereas cDNA constructed from splenic RNA was used by Mathews et al. Whatever the reason for the difference in sequences, the sequence found by us is more likely to reflect the real sequence of the CTS/Shi possessing resistant allele at Idd16 because the data are obtained directly from the NOD.CTS- $H$ - 2 congenic strain that is used for congenic mapping and identification of Idd16. Also, our results are able to explain the difference in reactivity with anti-K monoclonal antibodies seen in NOD and CTS mice in this and previous studies.

In summary, our nucleotide sequence analysis of the MHC class I K gene revealed that, while the NOD mouse has an identical sequence to $\mathrm{K}^{\mathrm{d}}$ type, the sequence in the CTS mouse was different from $\mathrm{K}^{\mathrm{d}}$ type at two amino acids that are seen in $\mathrm{K}^{\mathrm{k}}$ type. These sequence data are compatible with the immunoreactivity of the $\mathrm{K}$ molecule in this and previous studies. Given the function and the position of class I $\mathrm{K}$ gene, together with recent reports on the position and function of a second diabetogenic gene in the MHC, these data support the possibility that the class I K gene itself may be responsible for the Idd16 effect.

Acknowledgements. This study was supported by a Grantin-Aid for Scientific Research on Priority Areas, a Grant-in Aid for Scientific Research, a Grant-in-Aid for Exploratory Research and a Grant-in-Aid for Encouragement of Young Scientists, all from the Ministry of Education, Culture, Sports, Science and Technology of Japan. We thank Dr Masakazu Hattori at the Joslin Diabetes Center for providing monoclonal antibodies.

\section{References}

1. Castano L, Eisenbarth GS (1990) Type 1 diabetes: a chronic autoimmune disease of human, mouse, and rat. Annu Rev Immunol 8:647-679

2. Davies JL, Kawaguchi Y, Bennett ST et al. (1994) A genome-wide search for human type 1 diabetes susceptibility genes. Nature 8:130-136

3. Wicker LS, Todd JA, Perterson LB (1995) Genetic control of autoimmune diabetes in the NOD mouse. Annu Rev Immunol 13:179-200

4. Ikegami H, Ogihara T (1996) Genetics of insulin-dependent diabetes mellitus. Endocr J 43:605-613

5. Fujisawa T, Ikegami H, Kawaguchi Y et al. (1995) Class I HLA is associated with age-at-onset of IDDM, while class II HLA confers susceptibility to IDDM. Diabetologia 38:1493-1495

6. Park B, Lee S, Kim E et al. (2003) A single polymorphic residue within the peptide-binding cleft of MHC class I molecules determines spectrum of tapsin dependence. J Immunol 170:961-968

7. Kawabata Y, Ikegami H, Kawaguchi Y et al. (2000) Agerelated association of MHC class I chain-related gene A (MICA) with type 1 (insulin-dependent) diabetes mellitus. Hum Immunol 611:624-629 
8. Nakanishi K, Kobayashi T, Murase T et al. (1993) Association of HLA-A24 with complete beta-cell destruction in IDDM. Diabetes 42:1086-1093

9. Nesentsev S, Gombos Z, Laine AP et al. (2000) Nonclass II HLA gene associated with type 1 diabetes maps to the 240-kb region near HLA-B. Diabetes 49:22172221

10. Johansson S, Lie BA, Todd JA et al. (2003) Evidence of at least two type 1 diabetes susceptibility genes in the HLA complex distinct from HLA-DQB1, -DQA1 and -DRB1. Genes Immun 4:46-53

11. Valdes AM, Thomson G, Erlich HA, Noble JA (1999) Association between type 1 diabetes age of onset and HLA among sibling pairs. Diabetes 48:1658-1661

12. Hodgkinson AD, Millward BA, Demaine AG (2000) HLA-E locus is associated with age at onset and susceptibility to type 1 diabetes mellitus. Hum Immunol 61:290 295

13. Hattori M, Buse JB, Jackson RA et al. (1986) The NOD mouse: recessive diabetogenic gene in the major histocompatibility complex. Science 14:733-735

14. Prochazka M, Leiter EH, Serreze DV et al. (1987) Three recessive loci required for insulin-dependent diabetes in nonobese diabetic mice. Science 237:286-289

15. Wicker LS, Miller BJ, Coker LZ et al. (1987) Genetic control of diabetes and insulitis in the nonobese diabetic (NOD) mouse. J Exp Med 165:1639-1654

16. Wicker LS, Appel MC, Dotta F et al. (1992) Autoimmune syndromes in major histocompatibility complex (MHC) congenic strains of nonobese diabetic (NOD) mice. The NOD MHC is dominant for insulitis and cyclophosphamideinduced diabetes. J Exp Med 176:67-77

17. Prochazka M, Serreze DV, Worthen SM et al. (1989) Genetic control of diabetogenesis in NOD/Lt mice. Diabetes 38:1446-1455

18. Ikegami H, Eisenbarth GS, Hattori M (1999) Major histocompatibility complex-linked diabetogenic gene of the nonobese diabetic mouse. J Clin Invest 85:18-24

19. Ikegami H, Makino S, Yamato E et al. (1995) Identification of a new susceptibility locus for insulin-dependent diabetes mellitus by ancestral haplotype congenic mapping. J Clin Invest 96:1936-1942

20. Babaya N, Ikegami H, Kawagichi Y et al. (2000) Congenic mapping and functional analysis of a second component of the MHC-linked diabetogenic gene (Idd16). Int J Diabetes 8:1-7

21. Ikegami H, Makino S, Harada M et al. (1988) The cataract Shionogi mouse, a sister strain of the non-obese diabetic mouse: similar class II but different at class I gene products. Diabetologia 31:254-258

22. Hattoti M, Yamato E, Itoh N et al. (1999) Homologous recombination of the $\mathrm{MHC}$ class I $\mathrm{K}$ region defines new MHC-linked diabetogenic susceptibility genes in nonobese diabetic mice. J Immunol 163:1721-1724

23. Hattori M, Hattori K, Fujisawa T et al. (2003) MHC class I $\mathrm{K}^{\mathrm{d}}$ is diabetogenic in the NOD mouse. Diabetes 52 [Suppl 1]:A248 (Abstract)

24. Weiss E, Golden L, Zakut R et al. (1983) The DNA sequence of the $\mathrm{H}-2 \mathrm{~K}^{\mathrm{b}}$ gene: evidence for gene conversion as a mechanism for the generation of polymorphism in histocompatibility antigens. EMBO J 2:453-452

25. Kimura A, Israël A, Bail OL et al. (1986) Detailed analysis of the mouse $\mathrm{H}-2 \mathrm{~K}^{\mathrm{b}}$ promoter: enhancer-like sequences and their role in the regulation of class I gene expression. Cell 44:261-272
26. Kvist S, Roberts L, Dobberstein B (1983) Mouse histocompatibility genes: structure and organisation of a $\mathrm{K}^{\mathrm{d}}$ gene. EMBO J 2:245-254

27. Arnold B, Burgert HG, Archibald AL et al. (1984) Complete nucleotide sequence of the murine $\mathrm{H} 2-\mathrm{K}^{\mathrm{k}}$ gene. Comparison of three H-2K locus alleles. Nucleic Acids Res 12:9473-9487

28. Girgis KR, Capra JD, Stroynowski I (1995) Nucleotide sequence of $\mathrm{H} 2^{\mathrm{g} 7} \mathrm{~K}$ and $\mathrm{D}$ loci of nonobese diabetic mice. Immunogenetics 41:386

29. Mathews CE, Graser RT, Serreze DV et al. (2000) Re-evaluation of the major histocompatibility complex genes of the NOD-progenitor CTS/Shi strain. Diabetes 49:131134

30. Wicker LS, Leiter EH, Todd JA et al. (1994) Beta 2-microglobulin-deficient NOD mice do not develop insulitis or diabetes. Diabetes 43:500-504

31. Serreze DV, Leiter EH, Christianson GJ et al. (1994) Major histocompatibility complex class I-deficient NOD-B2 $\mathrm{m}^{\text {nul }}$ mice are diabetes and insulitis resistant. Diabetes 43:505509

32. Sumida T, Furukawa M, Sakamoto A et al. (1994) Prevention of insulitis and diabetes in $\beta 2$-microglobulin-deficient non-obese diabetic mice. Int Immunol 6:1445-1449

33. Perarnau B, Siegrist CA, Gillet A et al. (1990) $\beta 2$-microglobulin restriction of antigen presentation. Nature 346:751754

34. Katz J, Benoist C, Mathis D (1993) Major histocompatibility complex class I molecules are required for the development of insulitis in non-obese diabetic nice. Eur J Immunol 23:3358-3360

35. Anderson B, Park B, Verdaguer J et al. (1998) Prevalent $\mathrm{CD} 8+\mathrm{T}$ cell response against one peptide/MHC complex in autoimmune diabetes. Proc Natl Acad Sci USA 96:9311-9316

36. Dilorenzo TP, Graser RT, Ono T et al. (1998) Major histocompatibility complex class I-restricted T cells are required for all but the end stages of diabetes development in nonobese diabetic mice and use a prevalent $\mathrm{T}$ cell receptor $\alpha$ chain gene rearrangement. Proc Natl Acad Sci USA 95:12538-12543

37. Santamaria P, Utsugi T, Park BJ et al. (1995) Beta-cellcytotoxic CD8+ $\mathrm{T}$ cells from nonobese diabetic mice use highly homologous $\mathrm{T}$ cell receptor $\alpha$-chain CDR3 sequences. J Immunol 154:2494-2503

38. Wong FS, Visintin I, Wen L et al. (1996) CD8 T cell clones from young nonobese diabetic mice (NOD) islets can transfer rapid onset of diabetes in NOD mice in the absence of CD4 cells. J Exp Med 183:67-76

39. Taki T, Nagata M, Ogawa W et al. (1991) Prevention of cyclophosphamide-induced and spontaneous diabetes in NOD/Shi/Kbe mice by anti-MHC class $\mathrm{I} \mathrm{K}^{\mathrm{d}}$ monoclonal antibody. Diabetes 40:1203-1209

40. Boulard O, Damotte D, Deruytter N et al. (2002) An interval tightly linked to but distinct from the $\mathrm{H} 2$ complex controls both overt diabetes (Idd16) and chronic experimental autoimmune thyroiditis (Ceat1) in nonobese diabetic mice. Diabetes 51:2141-2147

41. Babaya N, Ikegami H, Fujisawa T et al. (2002) Sequence analysis of $\operatorname{Tn} f$ as a candidate gene for Idd16. Autoimmunity 35:63-66

42. Robles DT, Eisenbarth GS, Wang T et al. (2002) Identification of children with early onset and high incidence of anti-islet autoantibodies. Clin Immunol 102:217224 
43. Gupta M, Nikitina-Zake L, Zarghami M et al. (2003) Association between the transmembrane region polymorphism of MHC class I chain related gene-A and type 1 diabetes mellitus in Sweden. Hum Immunol 64:553561

44. Fennessy M, Metcalfe K, Hitman GA et al. (1994) A gene in the HLA class I region contributes to susceptibility to IDDM in the Finnish population. Childhood Diabetes in Finland (DiMe) Study Group. Diabetologia 37:937944
45. Todd JA, Bell JI, McDevitt HO (1987) HLA-DQ $\beta$ gene contributes to susceptibility and resistance to insulindependent diabetes mellitus. Nature 329:599-604

46. Lund T, O'Reilly L, Hutchings P et al. (1990) Prevention of insulin-dependent diabetes mellitus in non-obese diabetic mice by transgenes encoding modified I-A $\beta$-chain or normal I-E $\alpha$-chain. Nature 345:727-729

47. Perarnau B, Siegrist CA, Gillet A et al. (1990) ß2-microglobulin restriction of antigen presentation. Nature 346:751754 